\title{
Deregulated Electricity Market and Auctions: The Italian Case
}

\section{Luca Grilli}

Dipartimento di Scienze Economiche, Matematiche e Statistiche, Università degli Studi di Foggia, Largo Papa Giovanni Paolo II, Foggia, Italy.

Email:1.grilli@unifg.it

Received March $18^{\text {th }}, 2010$; revised May $14^{\text {th }}, 2010$; accepted June $27^{\text {th }}, 2010$.

\begin{abstract}
The Electricity Market (in Europe) undergoes a period of transformations never seen before. The competitive model suggested by the European Commission is based on a gradual increase in the classes of consumers able to choice, freely, their providers. In general, liberalization, deregulation, competition result in a spur to development and low prices for consumers. The Electricity Market isn't likely to follow such a rule. Electricity Markets are best described and analyzed as first-price multi-unit procurement iterated auctions. In this paper we present an analysis of the Italian case in order to show the effects of deregulation on final prices for users.
\end{abstract}

Keywords: Electricity Market, Auctions, Oligopoly, Deregulation

\section{Introduction}

The 1990s featured a wave of deregulation and privatization of electricity industries in several nations including the U.S., the U.K., Spain and Norway. In Italy this process started in 1992 (privatization of the Energy Pool "ENEL") ended in 2007 when the Electricity Market was created. Competition in production and sale has been focused in political debates related to electricity [1]. Notwithstanding that, deregulation and privatization of electricity industry did not result in lower prices for most electricity consumers. The inspiring policy backing the huge changes in electricity arrangements held on the following ideas:

1) Meeting customers' requirements, taking into due account the price, choice, quality and security of supply.

2) Enabling demand to be efficiently and economically met.

3) Allowing costs and risks to be efficiently reduced and shared.

4) Providing transparency.

5) Responding flexibly to circumstances.

6) Promoting competition in electricity markets, facilitating entry and exit for such markets.

7) Avoiding discrimination against particular energy sources.

8) Being compatible with government policies.
The overall objective was that "trading arrangements should deliver the lowest possible sustainable prices to all customers, for a supply that is reliable in both the short and the long run" (Electricity Pool, U.K. 1998).

In this paper the author shows the main features of Electricity Markets focusing his attention on the auction system. He considers the Italian case, showing that: without competition in production, expected price will equal the reserve price (related to the previous regulated price) and consequently, in this case, auctions are unnecessary and expensive. The market players in electricity industry are: producers, suppliers and traders. They are not mutually exclusive and, as a result, the producer may also supply electricity to final consumers. The author is going to show that the Italian case follows such a direction. In this case even the design of a particular auction [2] for discouraging collusion is useless.

The paper is organized as follows: in Section 2 the general features of Electricity Markets are presented, pointing out the attention on the topics of interest for the Italian case; in Section 3 the Italian case is studied; the last Section contains conclusions and comments.

\section{The Electricity Market}

In general, sale Electricity Markets are organized as multi-unit, uniform price auctions. Such markets are run daily by Indipendent System Operators (ISOs). Ordinarily there are two market systems: day-ahead auctions, 
held daily for each hour of the following day, and realtime auctions, held every five minutes during the day. The ISOs control both of them. Generators participate in these auctions by submitting offer curves consisting of generation level and energy prices (with other technical costraints). The ISO collects these offers and combines them with energy bids from load serving entities to construct the aggregate supply and demand curves. The ISOs use to clear the market in an Offer cost-minimizing way, they allocate energy contracts normally by using an optimization algorithm. Alternatively a Payment cost minimization may be adopted. Luh et al. $[3,4]$, show that Payment cost minimization problems return procurement costs relatively lower than those obtained under Offer cost-minimization. A complete analysis of these problems, which is not the main issue of this paper, can be found in Shunda [5].

The auction mechanism at work in these markets has two components; one related to the method of final payment and the other to the allocation of energy contracts among generators. The most used auctions methods are Uniform prices (pay market clearing price for the auction) and Discriminatory Prices (pay the offer price). The former has been adopted initially in the English Pool and it is the most common. In general the choice of pricing rule for electricity auctions is still being debated. Wolfram [6] presents arguments in favour of uniform electricity auctions, Rassenti et al. [7] go in the opposite direction presenting experimental evidence that discriminatory electricity auctions reduce volatility (but with higher average prices). Abbink et al. [8] provide an experimental analysis of this problem that is an ongoing debate about market design in the electricity industry. In general arguments are made in favour of the discriminatory one (England and Wales). Information (for the seller) plays a key role. For asymmetric information discriminatory auction is significantly less effective. In any case, with multi unit demand auctions it is difficult to make general theoretical statements (Ausubel and Cramton [9] summed up it very well).

The British regulating authorities thought that uniform auctions are more subject to strategic manipulation; the California Power Exchange goes in the opposite direction. Auction theorists are quite aware that discriminatory auction is not generally superior to uniform auction. In multi unit setting the comparison is even more complex. In the electricity market, other auction methods (for instance Vickrey auctions) haven't been properly considered.

Simple auctions, such as pay-your-bid and uniform price auctions, are neither in general optimal nor do they achieve productive efficiency (Léautier [10,11]). Competition both in production and sale has been focused on political debates related to electricity (Hunt [1]). Notwithstanding that, deregulation and privatization of elec- tricity industry did not result in lower prices to the largest electricity consumers. A huge literature shows the extensive evidence on the existence of generators' unilateral market power and resultant pricing above marginal cost (California: Puller [12]; England and Wales: Wolak et al. [13]; Texas: Hortaçsu et al. [14]).

A related (less studied) issue is the regulation of exchange of electricity between countries. It is a significant barrier to efficient electricity market formation. Empirical observation shows that transmission activity across markets has become increasingly important in all industrial countries. The European Electricity Market looks like a juxtaposition of individual markets rather than an integrated commodity market (see Finon [15]). The Florence Forum recommends to use the implicit auction method for managing cross-border congestion (the method consists of a pricing rule and an allocation rule based on the results realized in domestic markets) however the "Use it or Lose it" principle seems to have been widely adopted (the Italian case is very interesting in this direction as it will be shown in the next section).

\section{The Italian Case}

The Italian Power Exchange was born as a consequence of Bersani's law dated 16th march 1999; starting from the following year, customers had the possibility of stipulating bilateral contracts directly with freely selected providers. It was a deregulated market (over the counter); just after the year 2004 an Electricity Exchange has been created, it was committed to "Gestore del Mercato Elettrico" (GME). The Italian System is mixed, such as many European systems, in which a key role is played by public companies and an independent control authority. The transmission activity which is operated by the Government and the distribution activity are guaranteed in authorization system. The production activity is free and is carried out in a competitive system.

The main players of the market are: the National Transmission Network Manager "Gestore della Rete di Trasmissione Nazionale (GRTN)"; the Electricity Exchange Manager "Gestore del Mercato Elettrico (GME)"; Unique Buyer "Acquirente Unico (AU)"; the Network Owner "Terna S.p.A."; Electricity Producers.

The Italian Power Exchange consists of:

1) Electricity Markets (managed by the GME): dayahead market and adjustment market.

2) The Transmission Service Market.

Following the general framework presented in the previous section, it is evident that the Italian Power Exchange is a very complex system which has been created in order to obtain advantages for consumers which are typical of a competitive system. In general, liberalization, deregulation, competition result in low prices for users; the Italian Electricity Market seems not to follow such a rule. It will be shown that the motivation is structural and 
it is not dependent on the particular auction model utilized in the market, on the contrary the complex auction system, in this case, is an additional cost for users.

Market players are:

- Producers;

- Suppliers;

- Traders.

They are not mutually exclusive, as a result, the producer may also supply electricity to final users. The Italian situation is the following: The Government (directly or by means of controlled companies) controls the TERNA (the network owner), the ENEL (the most important Italian electricity producer) and the ENI (the only real competitor of ENEL). Such a situation leads to a lack of competition between producers. The lack of competition is also evident if we look at data concerning the percentage (Figure 1) of production which depends on cheap sources (nuclear and coal). Production is not performed in an efficient way. This is even more evident if we consider how the electricity production in Italy depends on oil: about $70 \%$ of electricity production depends on oil (the EU25 value is around 20\%). In the last five years the price of oil has increased more than $600 \%$, it is easy to imagine how it affects the price of electricity in Italy.

Consequently, the deregulated market results in a transaction cost which is added to the regulated price and because of this customers pay higher price if compared to the past (Figure 5). The four anomalies in the Italian power sector, which is almost unique in the international scene, are:

1) Italy is the biggest electricity importer in the world both in relative terms ( $13 \%$ of the internal demand) and absolute ones (this is even more significant since the Italian consumption is about $2 \%$ of the total consumption in the world);

2) Italy is the only country in the world which neither produce electricity with coal (limited to $15 \%$ ) nor with nuclear power;

3) Italy is the only country in the world which produces most of electricity by means of sources that are strictly connected with the oil quotation;

4) Italy is the only country in the world which produces about $50 \%$ of its electricity with natural gas imported, mostly, from abroad.

Because of this, the price of electricity, affected by these problems and connected also with the lack of a real competition between producers, is very high and cannot be reduced by a deregulation policy. If we consider the price evolution in the last years (Figure 2), it is evident that deregulation did not result in lower prices. If we look at the clearing prices (Figure 3) in a day in the North Italy zone, which is the more efficient, they are very high (from about 60 Euro/MWh up to 140 Euro/MWh). Since the prices of one day can depend on several factors, we show the average-max-min daily prices during ten days of November 2009 (Figure 4), and it appears that the prices are in the range (14 Euro/Mwh; 135 Euro/Mwh). In Figure 5 we plot the average yearly prices in Italy in the period 2004-2008, it is clear the increasing trend.

Another important feature which contributes on the price formation is the importation of electricity from

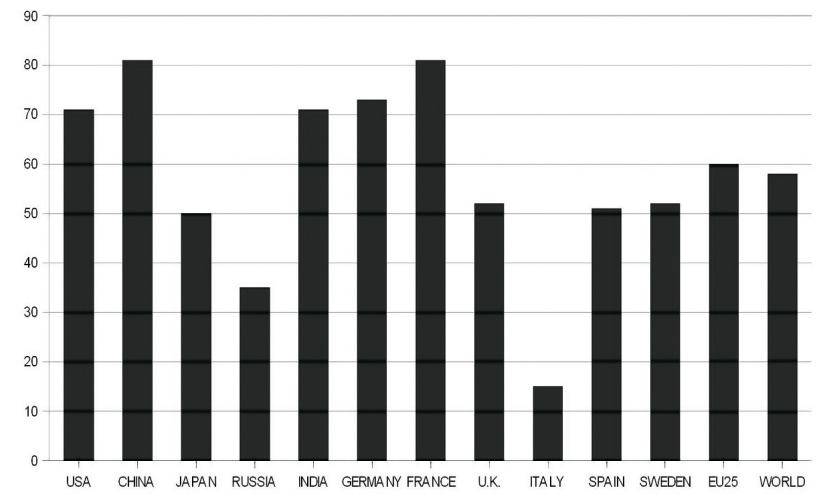

Figure 1. Cheap sources (coal and/or nuclear) in production activity (percentage).

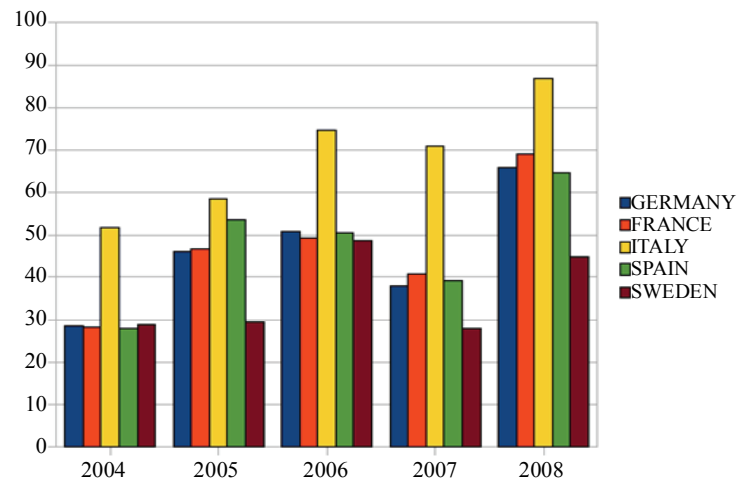

Figure 2. Average yearly prices (in Euros) of electricity in UE (data from GME).

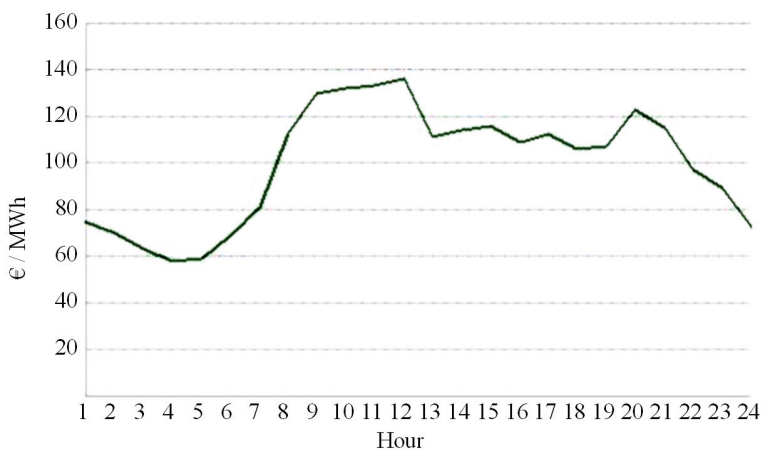

Figure 3. Electricity prices (Euro/Mwh) during the day in Northen Italy. 
Purchasing price - National Single Price (Euro/MWh)

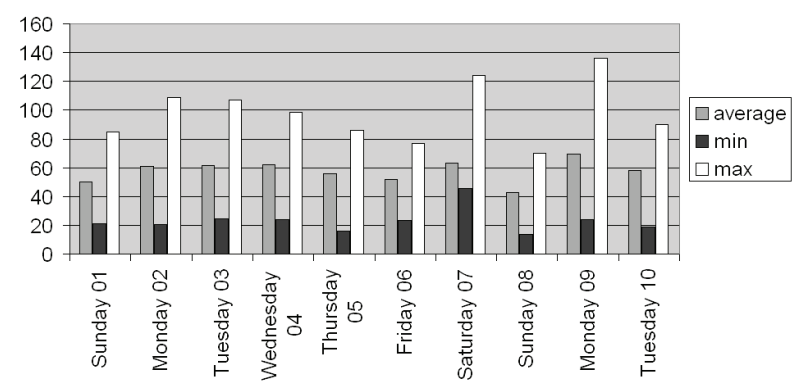

Figure 4. Daily summary for purchasing prices (Euro/Mwh) - November 2009 (source GME).

Purchasing Average price - National Single Price (Euro/MWh)

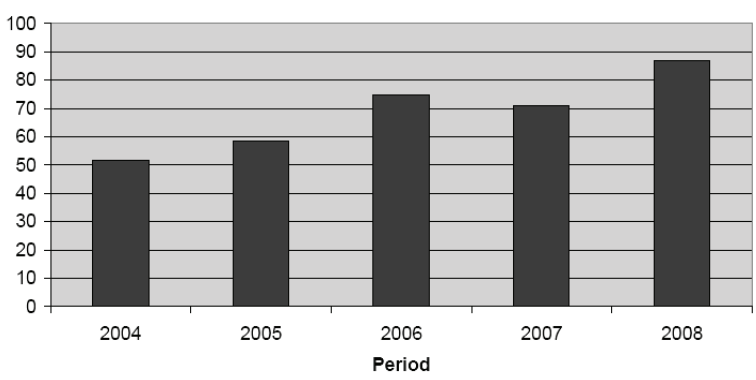

Figure 5. Italian single electricity price (Euro/Mwh).

abroad. In the previous section the author has stressed how this can be a barrier to efficiency in power markets.

The implicit auction method suggested by the Florence Forum ensures that prices paid for imported electricity is correlated with the internal market. However, above all in a country like Italy which is strictly dependent on importation, the "Use it or lose it" principle seems to have been widely adopted. So if the importation levels are around $70 \%$ of demand, and prices are not efficiently derived, the internal market cannot contribute in a relevant way to competitive prices formation.

Looking at the users, after two years of deregulation, over $98 \%$ of families has not changed provider and only $62 \%$ of families knows that electricity market has been deregulated.

It seems clear that, if the structural problems of production are not solved, any deregulated market system, also supported by sophisticated auction models, is useless and also costly.

\section{Conclusions}

In this paper the author analyzed the Italian Electricity market, in particular he has shown that the effects of deregulation are not appreciable compared with the aims which inspire such policies.

The reasons are not in the insights and techniques from auction theory used in such markets but they are structural and they depend on the absence of real competition between producers.

In Italy the government controls the two main producers of electricity and also the maintainer of the network. On the other hand, the production is dependent on costly sources like oil and natural gas that are mostly imported from abroad and so the costs of production are extremely high.

The standard procedure of introducing competition in regulated markets usually results in advantages to entrants; the Italian case is not in such direction. Switching towards more competition should imply increases in efficiency. In Italy deregulation resulted in increased transaction costs which destroy the advantages that competition was suppose to generate.

The main issue of this paper is that, if the production of electricity in Italy remains linked to costly sources imported from abroad, any deregulated market, designed also with a very sophisticated auction method, is not able to affect prices. This is even more evident if the importation of electricity is about $70 \%$ of demand and the prices for imported electricity is not linked with the internal market.

\section{REFERENCES}

[1] S. Hunt, "Making Competition Work in Electricity," John Wiley\&Sons, Inc., New York, 2002.

[2] L. Ausubel, "An Efficient Ascending-Bid Auction for Multiple Objects," The American Econimic Review, Vol. 94, No. 5, 2004, pp. 1452-11475.

[3] P. B. Luh, W. E. Blankson, Y. Chen, J. H. Yan, G. A. Stern, S. C. Chang and F. Zhao, "Payment Cost Minimization Auction for Deregulated Electricity Markets Using Surrogate Optimization," IEEE Transactions on Power Systems, Vol. 21, No. 2, 2006, pp. 568-578.

[4] P. B. Luh, W. E. Blankson, Y. Chen, J. H. Yan, G. A. Stern and F. Zhao, "Payment Cost Minimization with Demand Bids and Partial Capacity Cost Compensations for Day-Ahead Electricity Auctions," Electric Power Networks Efficiency and Security, Working Paper, University of Connecticut, Connecticut, 2005.

[5] N. Shunda, "Strategic Behavior in Day-Ahead and RealTime Markets for Electricity: Offer Cost or Payment Cost Minimization?" Working Paper, University of Connecticut, Connecticut, 2005.

[6] C. Wolfram, "Electricity Markets: Should the Rest of the World Adopt the UK Reforms?" Regulation, Vol. 22, No. 4, 1999, pp. 48-53.

[7] S. Rassenti, V. Smith and B. Wilson, "Discriminatory Price Auctions in Electricity Markets: Low Volatility at the Expense of High Price Levels," Journal of Regulatory Economics, Vol. 23, No. 2, 2003, pp. 109-123. 
[8] K. Abbink, J. Brandts and T. McDaniel, "Asymmetric Demand Information in Uniform and Discrimintory Call Auctions: An Experimental Analysis Motivated by Electricity Markets," Journal of Regulatory Economics, Vol. 23, No. 2, 2003, pp. 125-144.

[9] L. Ausubel and P. Cramton, "Demand Reduction in Multi-Unit Auctions with Varying Numbers of Bidders: Theory and Evidence from a Field Experiment," Working Paper, University of Maryland, Maryland, 2002.

[10] T. O. Léautier, "Transmission Constraints and Imperfect Markets in Power," Journal of Regulatory Economics, Vol. 19, No. 1, 2001, pp. 27-54.

[11] T. O. Léautier, "Electricity Auctions," Journal of Economics \& Management Strategy, Vol. 10, No. 3, 2001(a), pp. 331-358.

[12] S. L. Puller, "Pricing and Firm Conduct in California's
Deregulated Electricity Market," Review of Economics and Statistics, Vol. 89, No. 1, 2007, pp. 75-87.

[13] F. A. Wolak and R. H. Patrick, "The Impact of Market Rules and Market Structure on the Price Determination Process in the England and Wales Electricity Market," Working Paper 8248, National Bureau of Economic Research, 2001.

[14] A. Hortaçsu and S. L. Puller, "Understanding Strategic Bidding in Multi-Unit Auctions: A Case Study of the Texas Electricity Spot Market," The RAND Journal of Economics, Vol. 39, No. 1, 2008, pp. 86-114.

[15] D. Finon, “L'Intégration des Marchés Electriques Européens: de la Juxtaposition de Marchés Nationaux à l'Etablissement d'un Marché Régional," Economies et Societes, Vol. 37, No. 1-2, 2001, pp. 55-87. 